\title{
Tribological properties of fabric self-lubricating liner based on organic montmorillonite (OMMT) reinforced phenolic (PF) \\ nanocomposites as hybrid matrices
}

Bingli Fan ${ }^{1,2}$, Yulin Yang ${ }^{2}$, Chan Feng ${ }^{2,3}$, Jian Ma ${ }^{1,2}$, Yang Tang ${ }^{2}$, Yu Dong ${ }^{4}$, Xiaowen $\mathrm{Qi}^{1,2 *}$

${ }^{1}$ School of Mechanical Engineering, Yanshan University, Qinhuangdao 066004, P. R. China

${ }^{2}$ Aviation Key Laboratory of Science and Technology on Generic Technology of Self-Lubricating Spherical Plain Bearing, Yanshan University, Qinhuangdao 066004, P. R. China

${ }^{3}$ Nanyang Explosion Protection Group CO., LTD, Nanyang 473008, P. R. China

${ }^{4}$ Department of Mechanical Engineering; School of Civil and Mechanical Engineering, Curtin University, Perth, WA 6845, Australia

*Corresponding author: X. Qi E-Mail: qxw_tougao@163.com Tel: +86 0335-8077601 Fax: +86 0335-8077601 
Abstract: Organic montmorillonite (OMMT) reinforced phenolic (PF) nanocomposites with OMMT contents of 2 and $5 \mathrm{wt} \%$ were fabricated by the two-step OMMT intercalation process, resulting in the further increase of interlayer spacing of OMMT from $2.07 \mathrm{~nm}$ to $4.27 \mathrm{~nm}$. Prepared OMMT/PF composites were found to possess a mix of intercalated and agglomerated clay structures via X-ray diffraction (XRD) analysis and transmission electron microscopy (TEM). TG-DTG and DSC results revealed that the thermal stability of PF matrices was enhanced by the incorporation of OMMT. With OMMT/PF nanocomposites as hybrid matrices, fabric self-lubricating liners were prepared to evaluate their tribological properties. Effects of OMMT on friction coefficient, wear loss and wear morphology of fabric self-lubricating liner, based on OMMT/PF nanocomposites, were studied via long-term friction and wear tests. Tribological properties of liners with different OMMT contents were investigated by imitating high velocity/light load condition. The addition of OMMT appears to enhance the friction and wear properties of fabric self-lubricating liner and the preferable addition content of the OMMT is around $2 \mathrm{wt} \%$.

Keywords: Organic montmorillonite (OMMT), intercalation, fabric self-lubricating liner, tribological property

\section{Introduction}

The fabric self-lubricating liner is a kind of woven polymer composites, which are widely used in numerous industrial fields, such as self-lubricating spherical plain bearings, journal bearings and aerospace [1-3]. As a solid lubrication material, the fabric self-lubricating liner is characterized by low friction, high mechanical strength and impact resistance, good designability and cost-effectiveness. These excellent engineering and economic merits promote the fabric self-lubricating liner as a leading approach of solid lubrication, especially in aerospace applications. However, the rapid development of the aviation and space industries requires much harsher service environment for self-lubricating components. Therefore, the improvement for tribological properties of the fabric self-lubricating liner, when directly associated with the service life of self-lubricating components, becomes an urgent issue. Owing to the weave structure, varying weave parameters have been proven to be an efficient approach to enhance tribological and mechanical properties of fabric self-lubricating liner [4-5].

Nanotechnology offers a novel route to fabricate new materials with excellent mechanical, thermal, electrodynamic and tribological properties, etc [6-8]. This has been drawn the great attention for over a decade. The combination of well dispersed nanofillers/nanomaterials and polymers gives birth of a new hybrid material-polymer nanocomposites, which have provided increasing applications in different fields [9-13]. Nanotechnology has been inevitably employed in tribological modifications of various polymers or polymer composites. This effort started with dispersing nanofillers into polymer matrices [14-17] with some good progress. Wetzel et.al [14] found that 1-2 vol\% nano $\mathrm{Al}_{2} \mathrm{O}_{3}$ efficiently improved mechanical and tribological properties of epoxy resin. Furthermore, an extra addition of $\mathrm{CaSiO}_{3}$ microparticles produced a synergistic effect, which further enhanced the wear resistance and stiffness of epoxy composites [14]. With $20 \mathrm{wt} \%$ nano $\mathrm{Al}_{2} \mathrm{O}_{3}$, wear resistance of the polytetrafluoroethylene (PTFE) were improved by 600\% [17]. However, it was not long before people found the significant impact of pretreatment and dispersion of nanofillers on improved properties of polymer composites [18, 19]. Zhang and coworkers [20] studied the tribological performances of epoxy nanocomposites reinforced with surface-modified nanosilica. Their results indicated a much higher tribological performance with the enhanced efficiency of surface-treated nanosilica than untreated counterpart [20]. Recently, fabricated polyimide/modified graphene nanocomposites with strong filler-matrix interfaces, result in the significant increase of their wear resistance by 20 folds [21]. 
Further study [22] on polyimide/graphene oxide nanocomposites also demonstrated much better tribological properties under seawater-lubricated condition.

However, raw nanofillers are unfavorable for ever-increasing demand in polymer composites. Surface modifications such as covalent grafting of small segments can be time-consuming and costly with multi-step treatments. Accordingly, silicate mineral becomes more competitive nanofiller candidate since they have been successfully incorporated into continuous polymer matrices as reinforcements/fillers for a very long time [23, 24]. Taking advantage of the broadened interlayer spacing of well-dispersed silicate minerals, intercalated structure occurs when polymer chains are penetrated into interlayer areas to form polymer/layered silicate (PLS) nanocomposites. The nanosized effect and adsorption capacity of silicate lamellas offer excellent mechanical property, flame resistance and thermal property of PLS nanocomposites [25]. One of typical and widely used silicate minerals is montmorillonite (MMT) [26-29]. Polyfluoralkyl organophilic layered Na-MMT improved both mechanical and tribological properties of polydiene urethanes [30,31]. The natural layered structure of silicate makes it possess good solid lubrication [32] with the well-studied interaction mechanism [33]. Pre-treatment or modification of silicate is essential to enlarge the interlayer spacing prior to the actual fabrication of PLS nanocomposites. In general, there are three types of composites to be classified, which include immiscible microcomposites with the phase separation and no increase of interlayer spacing, intercalated nanocomposites where polymer molecules are inserted into clay interlayers to broaden their spacing, as well as exfoliated nanocomposites consisting of individual silicate sheets uniformly dispersed into continuous polymer matrices [34]. Phenolic resin/MMT nanocomposites were prepared by the suspension condensation [35] and intercalative polymerization [36]. It was proposed that the exfoliation-adsorption and in situ condensation mechanism, contributing to the formation [35] and thermal stability of nanocomposites, was improved owing to the chemical structure of organic modifiers [36].

In this paper, the Na-MMT was used to undergo two-step intercalation treatment in order to obtain OMMT/PF nanocomposites, which worked as hybrid matrices to be combined with the woven fabric for fabricating self-lubricating liner. Several tribological tests were performed to evaluate its tribological performances. The objective of this research is to extend the service life of products containing fabric self-lubricating liner by means of improving the tribological properties of liner composites.

\section{Experimental}

\subsection{Fabrication of OMMT/PF nanocomposites}

Ultrasonication method was used to fabricate OMMT/PF nanocomposites. The "cavitation effect" of ultrasonic waves is able to create a suitable microenvironment for the intercalation treatment [37]. Firstly, OMMT nanoparticles were prepared by organic modification through the ion exchange of $\mathrm{NH}^{4+}$ from cetyl trimethyl ammonium bromide (CTAB, purity $>99 \%$, Tianjin Kemiou Chemical Reagent Co., Ltd., China) for the first-step intercalation treatment. Then OMMT nanoparticles were mixed with PF to conduct the second-step intercalation treatment to obtain OMMT/PF nanocomposites. Replacement reaction occurred between the $\mathrm{Na}^{+}$from Na-MMT (average particle diameter $=100 \mathrm{~nm}$, ion exchange capacity IEC $=100 \mathrm{mmol} / 100 \mathrm{~g}$, Zhejiang FengHong New Material Co. Ltd., China) and the $\left[\mathrm{C}_{16} \mathrm{H}_{33}\left(\mathrm{CH}_{3}\right)_{3} \mathrm{~N}\right]^{+}$from CTAB that allows the organic $\left[\mathrm{C}_{16} \mathrm{H}_{33}\left(\mathrm{CH}_{3}\right)_{3} \mathrm{~N}\right]^{+}$to penetrate into Na-MMT interlayer areas, and also alter the polarity of Na-MMT. Thus, the interlayer spacing of MMT was expanded. The reaction schematic equation and the reaction diagram are shown as Eq. (1) and Fig. 1, respectively: 


$$
\mathrm{Na}+\mathrm{MMT}+\left[\mathrm{C}_{16} \mathrm{H}_{33}\left(\mathrm{CH}_{3}\right)_{3} \mathrm{~N}\right]^{+} \Leftrightarrow \mathrm{MMT}-\left[\mathrm{C}_{16} \mathrm{H}_{33}\left(\mathrm{CH}_{3}\right)_{3} \mathrm{~N}\right]^{+}+\mathrm{Na}^{+}
$$

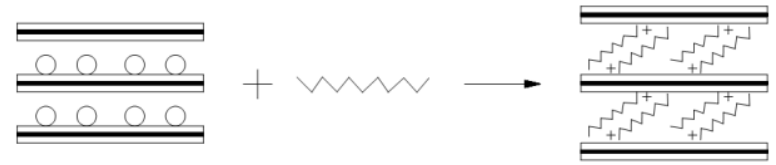

Fig. 1 The organic modification of Na-MMT

As for the intercalation treatment of Na-MMT with CTAB, initially Na-MMT ( $5 \mathrm{~g})$ and deionized water $(200 \mathrm{~mL})$ were mixed in a $500 \mathrm{~mL}$ beaker and stirred in high speed for $20 \mathrm{~min}$ using a magnetic stirring apparatus with the heat collection (DF101B, Automize The Instrument Plant On The Earth of Jintan City, China). 5 g CTAB was then dissolved in deionized water and adequately stirred before being slowly added to the Na-MMT solution. After mechanically stirred at $80^{\circ} \mathrm{C}$ for $6 \mathrm{~h}$ and ultrasonic oscillated for $2 \mathrm{~h}$, the solution was stood until stratification. Subsequently, a vacuum pump was used for the suction filtration of the solution. Then the solution was washed with deionized water to detach the superfluous $\mathrm{Br}-\left(0.1 \mathrm{~mol} / \mathrm{ml} \mathrm{AgNO}_{3}\right.$ solution was used for titration, until without yellow precipitate). Finally, vacuum filtrated solid particles were dried at $100{ }^{\circ} \mathrm{C}$ for $12 \mathrm{~h}$. After being ground and sieved, OMMT particles were finally obtained. TEM images of Na-MMT and typical exfoliated structure of the OMMT are shown in Fig. 2.

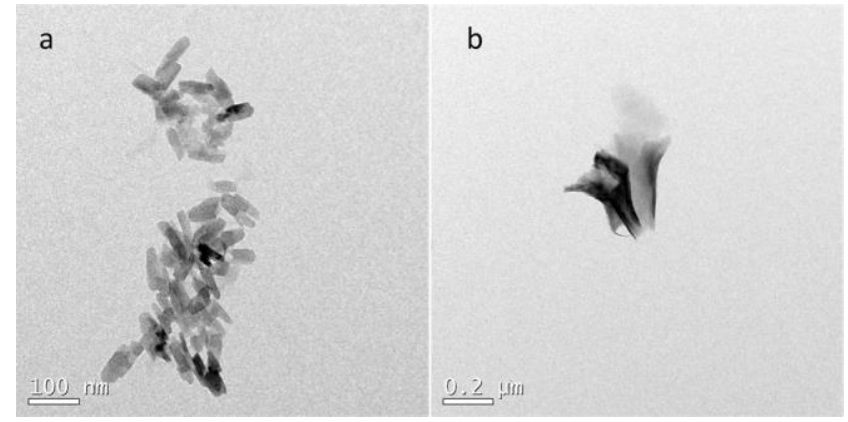

Fig. 2 TEM images of a) Na-MMT and b) OMMT

After the first-step intercalation treatment, OMMT nanoparticles were added into PF to conduct the second-step intercalation treatment. Quantitative PF (Material brand: 204, Shanghai Xinguang Chemical Co., Ltd., China) in a beaker was heated in water bath at $75^{\circ} \mathrm{C}$. Two different contents ( 2 and $5 \mathrm{wt} \%$ ) of OMMT were dissolved in absolute ethyl alcohol, stirred and ultrasonic vibrated for $15 \mathrm{~min}$, respectively. Then the solution was added to PF and stirred for $1 \mathrm{~h}$, further followed by the ultrasonic oscillation at $60^{\circ} \mathrm{C}$ for $3 \mathrm{~h}$. Finally, the solution was dried in an oven (DS-2510DTH, Shanghai Boxun Industry \& Commerce Co. Ltd., China) at $110{ }^{\circ} \mathrm{C}$ for $2 \mathrm{~h}$ to obtain OMMT/PF nanocomposites with different OMMT contents ( 2 and $5 \mathrm{wt} \%$ ).

\subsection{Tribological tests}

The fabric (shown in Fig. 3) was woven using ASL2000 Electronic Sample Loom, and the fabric parameters are shown in Table 1. Polytetrafluoroethylene (PTFE) fiber and aramid fiber (Kevlar 49) are commercially obtained from Shanghai Lingqiao Environment Protecting Equipment Works Co., Ltd., China and DuPont, U.S.A., respectively. The fabric was firstly soaked in acetone for $24 \mathrm{~h}$, boiled in distilled water for $20 \mathrm{~min}$ and dried at $80{ }^{\circ} \mathrm{C}$ for $1 \mathrm{~h}$. Then the dried fabric was immersed in a certain amount of OMMT/PF nanocomposites for $1 \mathrm{~h}$. A glass rod was used to roll out extra OMMT/PF nanocomposites and bubbles. Finally the soaked fabric was dried at $110{ }^{\circ} \mathrm{C}$ for $2 \mathrm{~h}$. Confocal laser scanning microscopy (CLSM) image of the fabric self-lubricating liner was shown in Fig. 4. When 
ring-on-block tribological tests were performed, the upper specimen was $45 \#$ steel ring with inner and outer diameters of $20 \mathrm{~mm}$ and $26 \mathrm{~mm}$, respectively. The lower specimen was the liner, which was bonded on the surface of the $45 \#$ steel substrate. To prepare the lower specimen, the substrate surface was polished successively using 320\# and 600\# waterproof abrasive paper and ultrasonically cleaned with absolute ethyl alcohol. Then the half-cured fabric was bonded on the substrate surface with PF. After being dried at $180{ }^{\circ} \mathrm{C}$ and $0.2 \mathrm{MPa}$ for $2 \mathrm{~h}$, the lower specimen was fabricated.

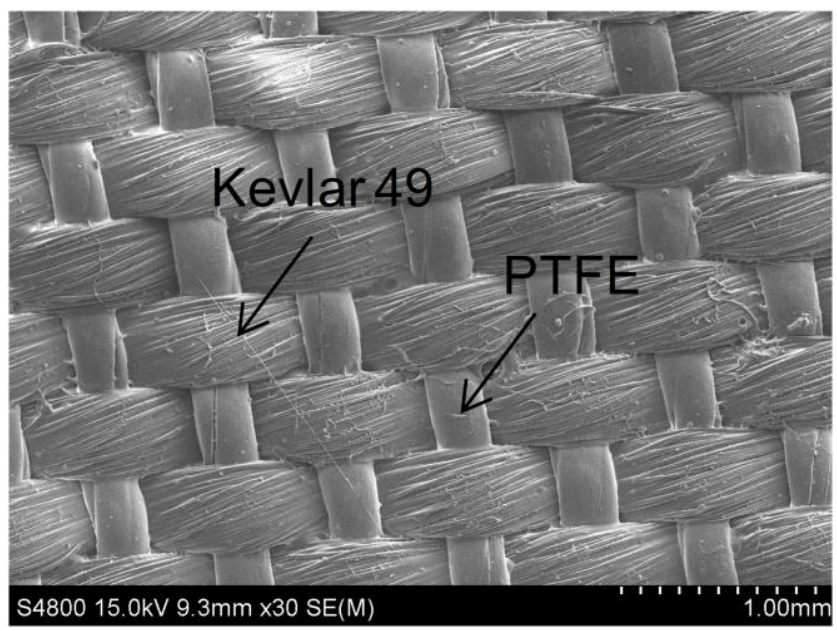

Fig. 3 SEM image of the woven fabric

Table 1 Parameters of the hybrid PTFE/Kevlar fabric

\begin{tabular}{cccccccc}
\hline Parameter & $\begin{array}{c}\text { Weave } \\
\text { structure }\end{array}$ & Warp & Weft & $\begin{array}{c}\text { Weft density } \\
(\text { thread } / 10 \mathrm{~cm})\end{array}$ & $\begin{array}{c}\text { Warp density } \\
(\text { thread/10cm })\end{array}$ & $\begin{array}{c}\text { Thickness } \\
(\mathrm{mm})\end{array}$ & $\begin{array}{c}\text { Areal density } \\
\left(\mathrm{g} / \mathrm{m}^{2}\right)\end{array}$ \\
$\begin{array}{c}\text { Fiber } \\
\text { fabric }\end{array}$ & $\begin{array}{c}\text { Weaving } \\
\text { plain }\end{array}$ & Kevlar 49 & PTFE & 209.6 & 231.6 & 0.37 & 280.5 \\
\hline
\end{tabular}

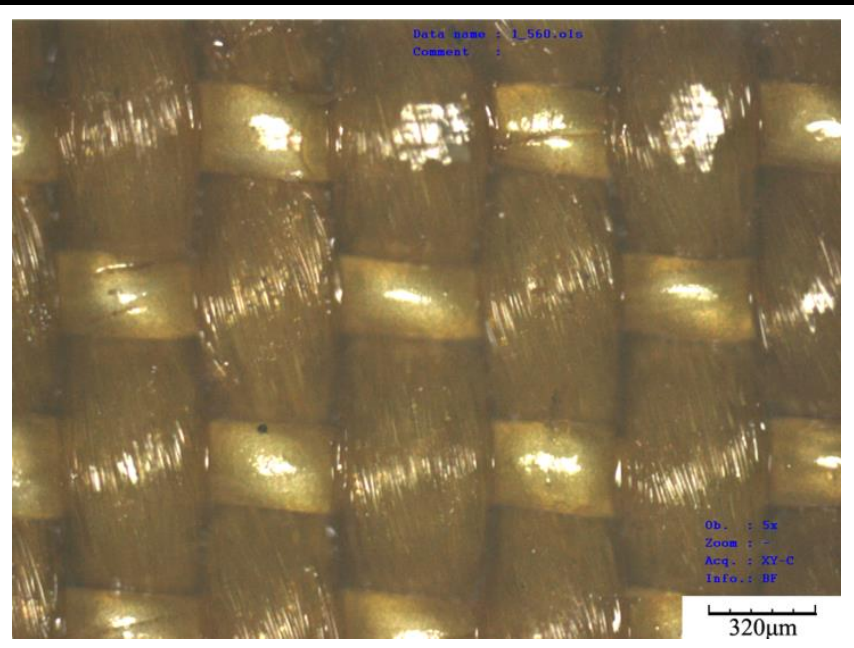

Fig. 4 CLSM image of the fabric self-lubricating liner

MMU-5G friction and wear tester (Fig. 5, Jinan SiDa Instruments Co., Ltd., China) was used to study the tribological properties of the fabric self-lubricating liner. Table 2 shows the experimental parameters under two different conditions: long-term friction test and high velocity/light load friction test (according to SAE AS81819 standard). The purpose of the long-term friction test was to study the variation of the friction coefficient, wear loss and wear morphology of the fabric self-lubricating liner with OMMT, as well as to evaluate the effect of OMMT on the tribological properties of the fabric self-lubricating liner. The high velocity/light load friction test can imitate the actual working condition 
of liner-containing parts such as journal bearings or spherical plain bearings. Each experiment was repeated three times to ensure the reliability and accuracy of the result data.

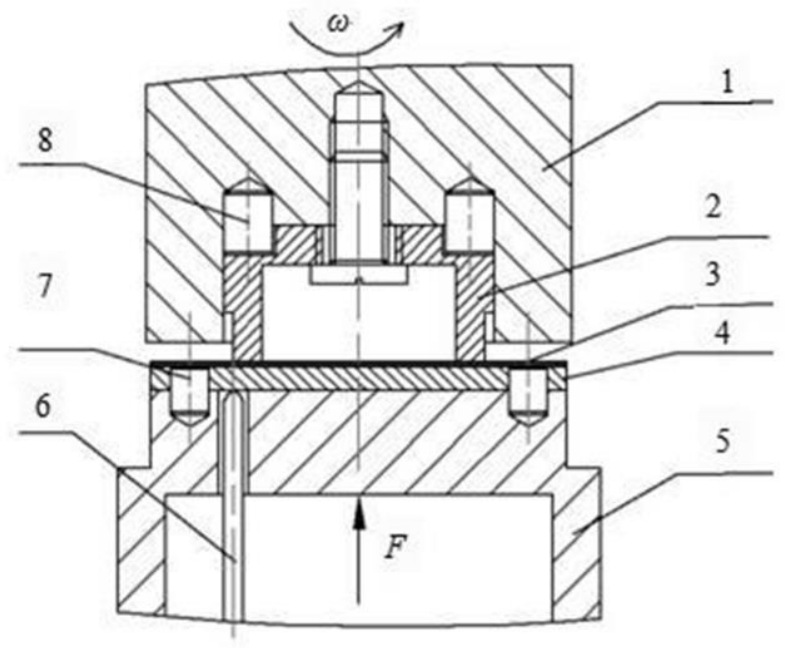

Fig. 5 MMU-5G friction and wear tester: 1-drive shaft, 2-upper specimen, 3-fabric liner, 4-substrate, 5- load shaft, 6-thermocouple, 7-lower torque pin, 8-upper torque pin

Table 2 Tribological test parameters

\begin{tabular}{ccccc}
\hline Test condition & Load (MPa) & Velocity (r/min) & Test time (h) & Temperature \\
Long-term & 2 & 500 & 44 & Room temperature \\
High velocity/light load & 10 & 500 & 6 & Room temperature \\
\hline
\end{tabular}

The friction coefficient can be recorded online by the tester and the wear rate can be calculated by Eq. (2). The thickness of each measurement point before friction was obtained utilizing YG141D thickness tester. To decrease the measurement error, 10 points on each fabric were measured each time to calculate an average value.

$$
w=\frac{1}{\mathrm{~N}} \sum_{i=1}^{\mathrm{N}}\left(H_{\mathrm{o} i}-H_{i}\right)
$$

where $w$ is the wear loss of the fabric self-lubricating liner, $\mathrm{N}$ is the measurement point number ( $\mathrm{N}=10), H_{\mathrm{o} i}$ is the original thickness of the chosen points and $H_{i}$ is the thickness of corresponding points of the sample after friction.

\section{Results and discussion}

\subsection{Characterization and analysis of the intercalation effect and OMMT/PF nanocomposites}

\subsubsection{X-ray diffraction (XRD) analysis}

Changes of OMMT interlayer spacing can lead to variations of crystal structures, which can be reflected directly by the position of the (001) crystal plane in the XRD pattern with Eq. (3) based on the Bragg's Law:

$$
2 d \sin \theta=n \lambda
$$

Where $d$ is the interlayer spacing of OMMT $(\mathrm{nm}), \theta$ is the diffraction angle $\left(^{\circ}\right), \lambda$ is the wavelengths of the X-ray and $n$ is the integer (for (001) crystal plane $n=1$ ).

XRD (D/MAX-RB, Japan) patterns of Na-MMT, OMMT, 2 wt\% OMMT/PF nanocomposite and 5 wt\% OMMT/PF nanocomposite are shown in Fig. 6. The (001) crystal plane of Na-MMT appeared in the position of $2 \theta=5.96^{\circ}$, which is corresponding to $d_{00 I}=1.48 \mathrm{~nm}$. However, after the MMT intercalation, the (001) peak was shifted to a smaller $2 \theta$ angle of $4.27^{\circ}$. The interlayer spacing of 
OMMT becomes $d_{001}=2.07 \mathrm{~nm}$, which is increased by $0.59 \mathrm{~nm}$.

By replacing the $\mathrm{Na}^{+}$with the $\left[\mathrm{C}_{16} \mathrm{H}_{33}\left(\mathrm{CH}_{3}\right)_{3} \mathrm{~N}\right]^{+}$, the first-step intercalation of the Na-MMT with CTAB expanded the MMT interlayer spacing. Therefore, the PF molecular chains more easily entered into the OMMT interlayers during the second-step intercalation treatment to further expand the interlayer spacing of the OMMT. This plays a vital role in the homogeneous and filler dispersion of the nano Na-MMT in PF.

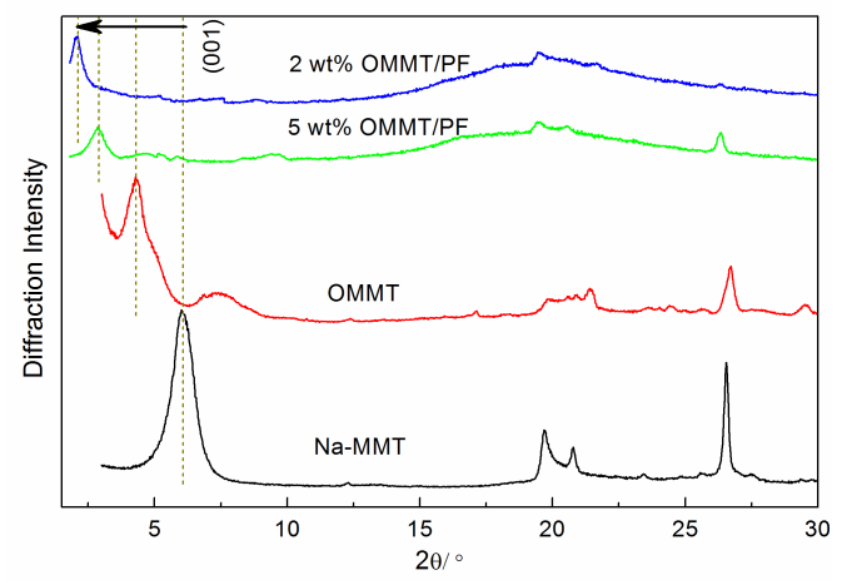

Fig. 6 XRD patterns of Na-MMT, OMMT, 2 wt $\%$ OMMT/PF composite and 5 wt $\%$ OMMT/PF composite (The curves are shifted vertically for clarity)

After the second-step intercalation, the (001) peak for OMMT/PF nanocomposites with OMMT contents of 2 and $5 \mathrm{wt} \%$ appeared at the positions of $2 \theta=2.10^{\circ}$ and $2.90^{\circ}$, corresponding to the increased interlayer spacings of $4.27 \mathrm{~nm}$ and $3.04 \mathrm{~nm}$, respectively, as opposed to that of OMMT. It is suggested that a higher level of OMMT intercalated structures are manifested, primarily taking place at the low OMMT content of $2 \mathrm{wt} \%$. This arises from the penetration of PF molecular chains into the interlayer areas of OMMT for their spacing expansion.

\subsubsection{TEM analysis}

The TEM (JEM-2010, Japan) images of OMMT/PF nanocomposite were shown in Fig. 7. Note that the bright area in the image represents the PF matrix and the dark area indicates the OMMT agglomerates. In the circled regions, it can be seen that the length of OMMT platelets is approximately $100 \mathrm{~nm}$. They were characterized by scatter, large interval and disordered orientation. Meanwhile, due to the insufficient shear stress to overcome the Van der Waals interactions among OMMT platelets, OMMT in the rectangular regions remained agglomerated. The OMMT morphology was consistent with former researches [35, 36, 38]. These observations further confirmed the morphology of OMMT/PF nanocomposites can be a quite complex with a mix of intercalated and agglomerated structures, in good accordance with the aforementioned XRD results.

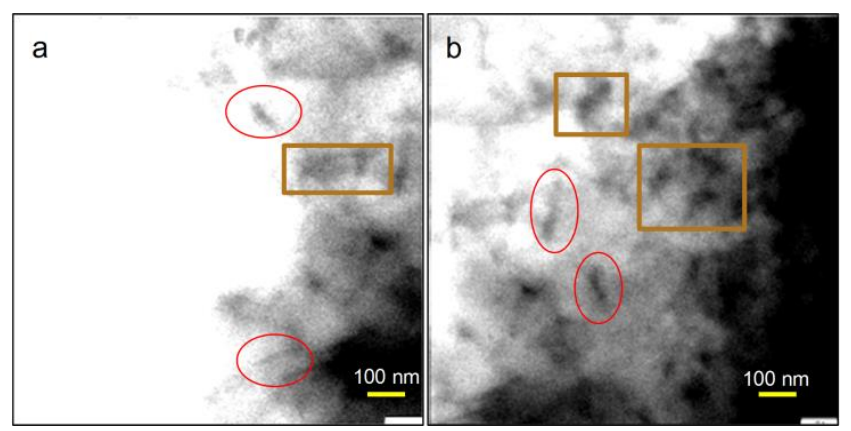

Fig. 7 TEM images of OMMT/PF composite with (a) 2 wt $\%$ OMMT and (b) 5 wt $\%$ OMMT 


\subsubsection{Fourier transform infrared spectroscopy}

Fig. 8 shows the FTIR (E55+FRA106) spectrograms of Na-MMT, OMMT, $2 \mathrm{wt} \%$ OMMT and 5 wt\% OMMT. In the curve of Na-MMT, the peak at $3431 \mathrm{~cm}^{-1}$ was assigned to the absorption peak for the surface hydroxyl (-OH) of MMT. The stretching vibration of Si-O-Si skeleton forms the strong absorption peak at $1070 \mathrm{~cm}^{-1}$. Bands from $400 \mathrm{~cm}^{-1}$ to $800 \mathrm{~cm}^{-1}$ belong to the inner vibration of Si-O tetrahedron and $\mathrm{Al}-\mathrm{O}$ octahedron. The vibrations at $860 \mathrm{~cm}^{-1}$ and $520 \mathrm{~cm}^{-1}$ were attributed to the flexural vibrations of Si-O-Al and stretching vibration of Si-O-Al, respectively. Both of them are typical infrared spectra of silicate. Compared with the FTIR spectrum of the Na-MMT, several distinct changes were observed in that of OMMT. Absorption peaks at $2851 \mathrm{~cm}^{-1}$ and $2920 \mathrm{~cm}^{-1}$ were created, which were in accordance with the unsymmetrical stretching vibration and symmetrical stretching vibration of $-\mathrm{CH}_{3}$, respectively. Furthermore, the flexural vibration of $-\mathrm{CH}_{2}$ forms the infrared peak at $1493 \mathrm{~cm}^{-1}$. These results indicate that organic macromolecular chains of CTAB penetrated into the silicate interlayer areas of the Na-MMT.

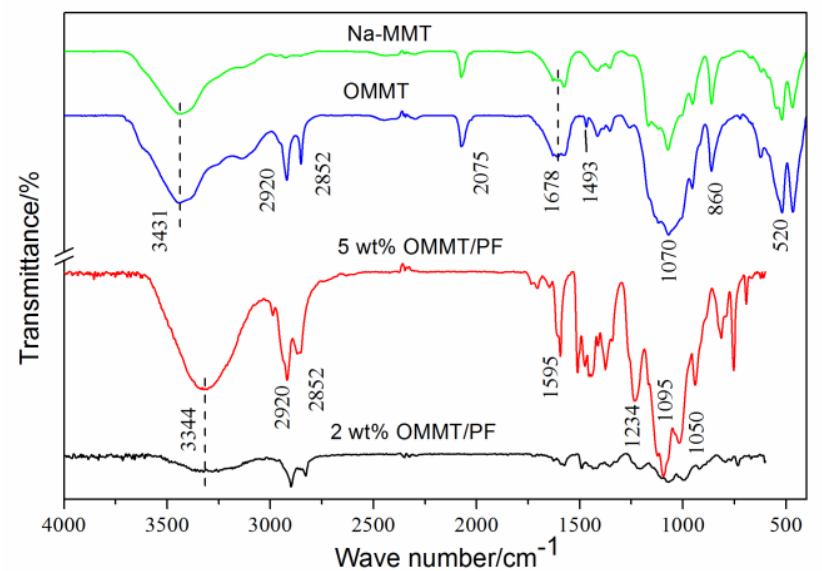

Fig. 8 FTIR spectrograms of Na-MMT, OMMT, 2 wt $\%$ OMMT and $5 \mathrm{wt} \%$ OMMT (The curves were shifted vertically for clarity)

As shown in the FTIR spectrograms of OMMT/PF nanocomposites with different OMMT contents in Fig. 8, the peak at $3344 \mathrm{~cm}^{-1}$ was created by the phenolic hydroxyl (-OH) stretching vibration of pure PF. Peaks at $1595 \mathrm{~cm}^{-1}, 1095 \mathrm{~cm}^{-1}$ and $1050 \mathrm{~cm}^{-1}$ were attributed to the $\mathrm{C}-\mathrm{H}$ stretching vibration in the benzene ring of PF, the stretching vibration of methylene ether linkage $\left(-\mathrm{CH}_{2}-\mathrm{O}-\mathrm{CH}_{2}-\right)$ and characteristic absorption spectrum of stretching vibration of methylol, respectively. The vibration peak at $1234 \mathrm{~cm}^{-1}$ was caused by the $\mathrm{C}-\mathrm{O}$ stretching vibration of the phenolic hydroxyl group. Chemical reactions between PF and hydroxyl group of OMMT might occur [37] with modified surface property of OMMT. Absorption peaks at $2852 \mathrm{~cm}^{-1}$ and $2920 \mathrm{~cm}^{-1}$, corresponding to the unsymmetrical stretching vibration and symmetrical stretching vibration of $-\mathrm{CH}_{3}$ for OMMT/PF nanocomposites with $2 \mathrm{wt} \%$ OMMT, become stronger and sharper than those of counterparts with 5 wt\% OMMT.

\subsubsection{Differential scanning calorimetry-thermogravimetry}

The TG (NETZSCH, Germany) and derivative thermogravimetry (DTG) curves of pure PF and OMMT/PF nanocomposites at OMMT contents of 2 and 5 wt\% are shown in Fig. 9. Comparing TG curves of three samples, when the temperature was below $260{ }^{\circ} \mathrm{C}$, the weight loss of all the samples was very low, which can be attributed to the loss of residual water in the material and further condensation of PF matrices. From the DTG curves of this stage the maximum degradation temperature $\left(T_{\max }\right)$ of both OMMT/PF nanocomposites shifted toward higher temperature (shown with arrow) with the lowered degradation rate. Moreover, the decomposition temperatures $\left(T_{d}\right.$, temperature at $10 \%$ 
weight loss) of PF, $2 \mathrm{wt} \%$ OMMT/PF nanocomposite and $5 \mathrm{wt} \%$ OMMT/PF nanocomposite were $145^{\circ} \mathrm{C}, 179^{\circ} \mathrm{C}$ and $241^{\circ} \mathrm{C}$, respectively. Clearly the thermal stability of the PF was enhanced by the incorporation of the OMMT, which was ascribed to the mass transport barrier role of MMT to the volatile product generated during decomposition [39]. The materials suffered from a main weight loss in the temperature range of $280--670^{\circ} \mathrm{C}$. During this stage, the oxidation of terminal hydroxyl and the pyrolysis of the free radical lead to the production of small molecular products such as $\mathrm{CH}_{4}, \mathrm{CO}, \mathrm{CO}_{2}$, $\mathrm{CH}_{2} \mathrm{O}, \mathrm{C}_{6} \mathrm{H}_{6}$ and phenol [40]. However, both OMMT/PF nanocomposites decomposed at a lower temperature than pure PF. This might be caused by the surfactant exchange of the Na-MMT with CTAB. Generally, CTAB can be decomposed at relatively low temperature [41] and accelerate the degradation of PF matrices as a catalyst [39].

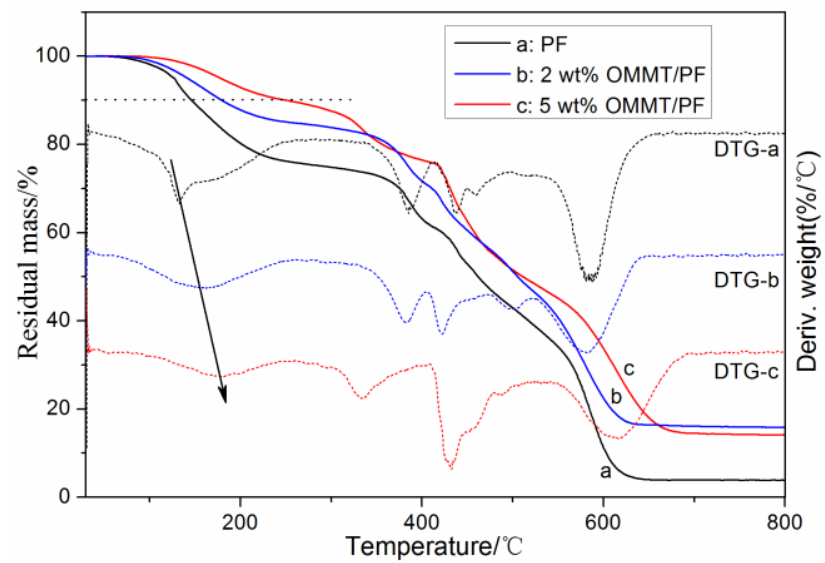

Fig. 9 TG and DTG curves of (a) pure PF; (b) 2 wt \% OMMT/PF nanocomposite and (c) 5 wt $\%$ OMMT/PF nanocomposite (DTG curves were shifted vertically for clarity)

For DSC curves shown in Fig. 10, obvious endothermic peaks of all samples were observed between 400 and $650{ }^{\circ} \mathrm{C}$. This was induced by the energy absorption that supports the segmental motion of polymer molecular chains. Between 400 and $550{ }^{\circ} \mathrm{C}$, endothermic peaks of both OMMT/PF nanocomposites were dense and intensive, which was caused by the overlap of the synchronous dehydroxylation decalescence of the OMMT and PF [39]. Moreover, temperatures of maximum endothermic peaks for all materials were $587^{\circ} \mathrm{C}(\mathrm{PF}), 580^{\circ} \mathrm{C}(2 \mathrm{wt} \% \mathrm{OMMT} / \mathrm{PF}$ composite $)$ and $614^{\circ} \mathrm{C}$ (5 wt\% OMMT/PF composite), respectively. It can be evident that the thermal stability of intercalated OMMT/PF nanocomposites was better than that of pure PF.

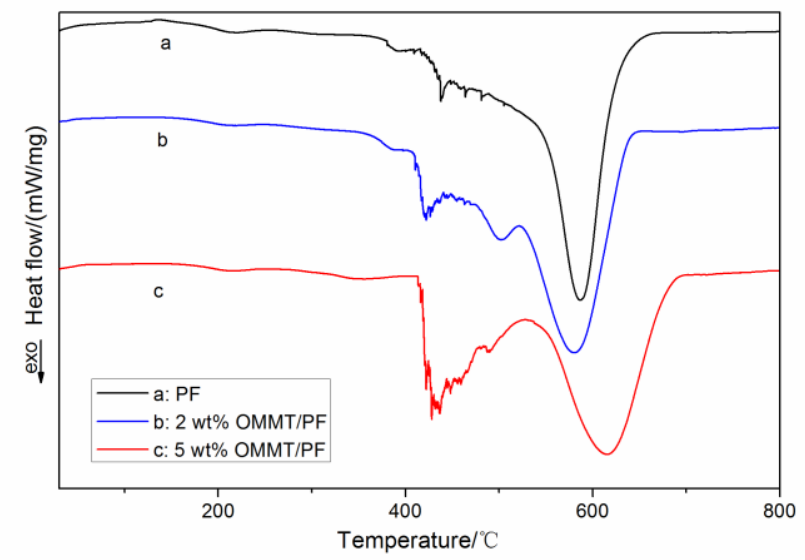

Fig. 10 DSC curve of (a) pure PF; (b) 2 wt $\%$ OMMT/PF nanocomposite and (c) 5 wt $\%$ OMMT/PF nanocomposite (curves were shifted vertically for clarity) 


\subsection{Long-term friction test}

\subsubsection{Friction and wear}

The average friction coefficient variations of different fabric self-lubricating liners and the friction coefficient curves during 0-4 h (Fig. 11a) and 10-14 h (Fig. 11b) for the fabric self-lubricating liner with OMMT contents of $2 \mathrm{wt} \%$ are shown in Fig. 11. Friction coefficients of all liners are basically at the same level at the early friction stage. As the friction time is over $28 \mathrm{~h}$, the average friction coefficients of the liners are apparently kept separate: liner with OMMT contents of $2 \mathrm{wt} \%$ shows the lowest friction coefficient while liner with OMMT content of 5 wt $\%$ exhibits the highest friction coefficient. Note that the friction tests were interrupted periodically for analysis. After interruptions, the lower specimen was cooled in air and removed from the tester to measure the wear loss and to investigate wear morphologies. Interruption internals were changed from $2 \mathrm{~h}$ in the early friction stage to $4 \mathrm{~h}$ in the later friction stage as the friction time increased. In fact, such interruption impacts the friction property of the friction pair [42]. As shown in Figs. 11a and b, after interruption $(2 \mathrm{~h}, 10 \mathrm{~h}$ and $12 \mathrm{~h}$ ), the friction coefficient of the fabric liner appears to go through a re-running-in period. However, such re-running-in period was shorter and steadier than the initial running-in period (see friction coefficient curve of $0-2 \mathrm{~h}$ in Fig. 11a). After re-running-in period, the friction coefficient immediately turned into a steady state and was kept at the similar level to the former friction stage. In general, the addition of proper OMMT content to the liner improves the antifriction property (low friction coefficient) of the fabric self-lubricating liner. However, the particle aggregation occurs in the case of high additive content [43], which is detrimental for the antifriction property of the fabric self-lubricating liner, as is the case of liner with $5 \mathrm{wt} \%$ OMMT.

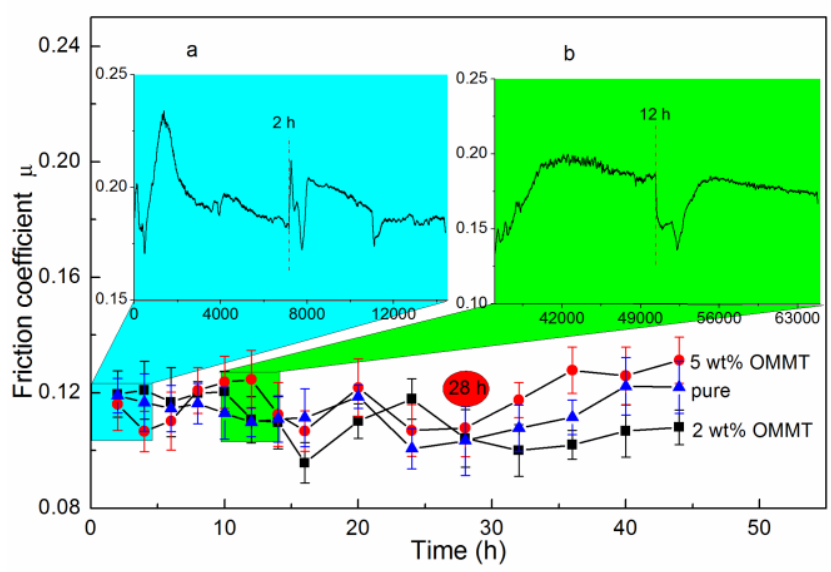

Fig. 11 Average friction coefficient of different fabric self-lubricating liner under long-term friction

Fig. 12 showed the wear losses of three kinds of fabric self-lubricating liners. As observed in Fig. 12 , the wear process of both pure liner and liner with $5 \mathrm{wt} \%$ OMMT was basically split into two stages through the experimental friction time: violent wear with rapid wear $(0-8 \mathrm{~h})$ and mild wear with slight and steady wear (8-44 h). However, wear loss curves of liner with $2 \mathrm{wt} \%$ OMMT seemed to present a monotone increasing trend through the experimental time, without any transition. At early wear stage $(0-8 \mathrm{~h})$, wear losses of both pure liner and liner with $5 \mathrm{wt} \%$ OMMT suffered from a rapid consumption but the wear loss of the liner with $2 \mathrm{wt} \%$ OMMT was lower than that of the others. Hereafter, the wear loss level was distinct in subsequent wear. The liner with $2 \mathrm{wt} \%$ OMMT shows the best wear resistance (lowest wear loss), followed by the liner with $5 \mathrm{wt} \%$ OMMT and pure liner. As the test finished after $44 \mathrm{~h}$, wear losses of the pure liner, liners with $2 \mathrm{wt} \%$ and $5 \mathrm{wt} \%$ OMMT were $0.233 \mathrm{~mm}, 0.132 \mathrm{~mm}$ and $0.170 \mathrm{~mm}$, respectively. Compared with the pure liner, wear loss of the liners with $2 \mathrm{wt} \%$ and 5 
wt $\%$ OMMT were decreased by $42 \%$ and $27 \%$, respectively. Overall, the appropriate addition of OMMT improves the wear resistance of fabric self-lubricating liner, particularly at the OMMT content of $2 \mathrm{wt} \%$.

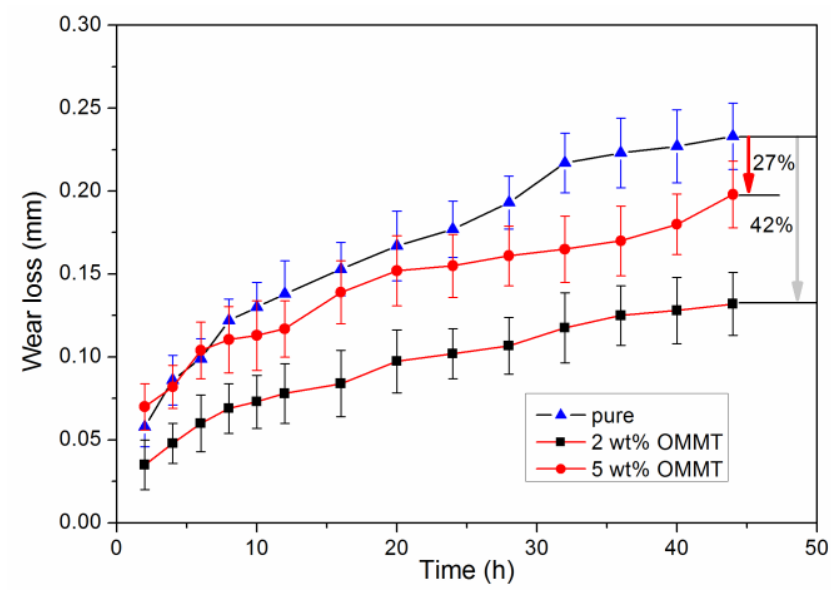

Fig. 12 Wear losses of different fabric self-lubricating liners under long-term friction

\subsubsection{Wear morphology}

CLSM wear morphologies of self-lubricating liners are shown in Fig. 13. In the running-in period (violent wear stage), the liner directly contacts with the steel counterpart, and the geometric characterization (surface apophasis) of both the liner and the counterpart significantly lowers the actual contact area, leading to the high pressure in the contact points and unstable tribological properties. Accompanied with the unstable friction and wear, a part of fabric material was pressed under plastic deformation, some PF matrices were separated from the fabric along with microcutting, pulling out and fracture of the fibers. Surface material of the liner was rapidly consumed and the fabric material (Kevlar and PTFE fibers) started to participate in friction. As shown in the corresponding images of lines $a$ and $b$ in Fig.15, wear debris stored in dents of the liner (circled areas in images $a-\alpha$ and $b-\alpha$ of Fig. 13) and the pure liner and liner with OMMT content of $2 \mathrm{wt} \%$ show smoother worn surface and lower wear than liner with OMMT content of $5 \mathrm{wt} \%$. As proceeding of the friction test, gathered friction heat results in the softening of liner surface fibers. Under shear stress, the surface fibers were further pressed, microcut and crushed into fragments consisting of OMMT/PF nanocomposite pieces, as well as PTFE and Kevlar debris. The part of the fragments was re-pressed on the liner surface, and some were adhered on the counterpart surface to form transfer film. As shown in line c of Fig. 13, the surface fibers were visibly pressed to deform and covered most of the friction area, especially for the liner with $5 \mathrm{wt} \%$ OMMT shown in image c- $\gamma$ of Fig. 13. On the one hand, the transfer film lowered the roughness of the friction pair; on the other hand, it blocked the direct contact of the liner and its counterpart, which converted the friction pattern to transfer film--surface material of the liner. The transfer film on the counterpart surface was continuously removed and resupplied. This repetitive action last throughout the remaining wear process. As shown in line d of Fig. 13, the difference of wear morphology for the liners was much more evident. Weave structure of the worn surface for the pure liner was barely recognized, but the lubricating layer was visible (image d- $\alpha$ in Fig. 13). Differently, surface fibers of the liner with $2 \mathrm{wt} \%$ OMMT was fully pressed to spread out the friction surface and the weave structure was clearly observed as shown in image $d-\beta$ in Fig. 13. Wear grooves also appeared in sight. For the liner with $5 \mathrm{wt} \%$ OMMT, weave structure of the worn surface was reluctantly recognized, but the wear was severe with obvious and deep wear grooves shown in image d- $\gamma$ of Fig. 13. One phenomenon can be observed from Fig. 13 is that the structural integrity of both liners with 
OMMT was better than that of pure liner. This is attributed to improved mechanical properties of OMMT/PF nanocomposite [25], leading to the improvement of liner mechanical properties. When the friction is applied, the better mechanical strength supplies a higher load-capacity and wear resistance for the liner. Furthermore, the solid lubrication effect of MMT [32] also reduces the shear deformation in the repetitive friction actions, which protects the surface material from quick removal and decreases wear rate.

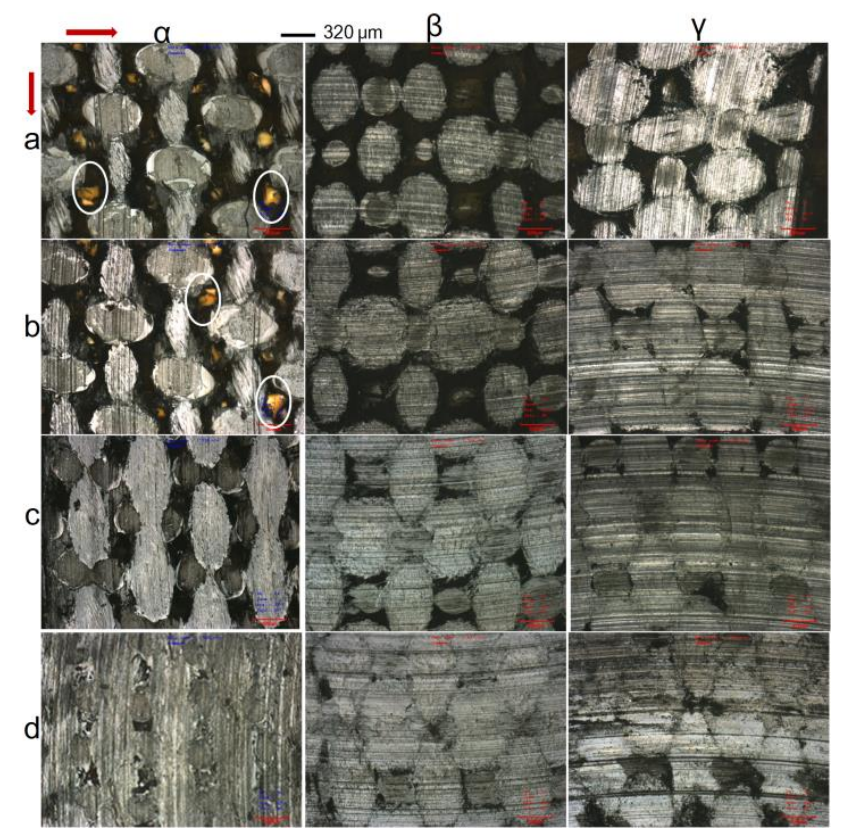

Fig. 13 CLSM wear morphologies of the self-lubricating liners under long-term friction: rows $\alpha, \beta$ and $\gamma$ indicate the pure liner and liners with $2 \mathrm{wt} \%$ and $5 \mathrm{wt} \%$, respectively; lines of a, b, c and d indicate the worn image at friction time of $2 \mathrm{~h}, 6 \mathrm{~h}, 20 \mathrm{~h}$ and $44 \mathrm{~h}$; all images share the same scale

\subsection{High velocity/light load friction test}

Fig. 14 shows the friction coefficient of different liners under a high velocity/light load condition. At the early friction stage, friction coefficients of both pure liner and liner with $5 \mathrm{wt} \%$ OMMT started with monotonic decrease until the steady friction is reached. However, the friction coefficient of liner with $2 \mathrm{wt} \%$ OMMT firstly increased to the maximum and then sharply dropped to the same level of pure liner. After such adjustment, the friction coefficient slowly entered into the steady friction state. This might be caused by the enhanced capacity of Na-MMT for separating from the polymer matrix and intensified transfer property to the counterface [30], which favors the quick formation of the transfer film and steady tribosurface. With a focus on the start time of $600 \mathrm{~s}$, a slight increase in friction coefficient of both liners with 2 and 5 wt $\%$ OMMT was observed, especially for the liner with 2 wt $\%$ OMMT. Comparatively, friction coefficient of pure liner steadily decreased. When the liner was fabricated with OMMT/PF nanocomposite, the addition of OMMT increased the roughness of the liner. In the early friction stage (running-in period), the liner started with a high friction coefficient and went through fluctuations. When the friction coefficient turned into the steady stage, friction coefficient curves of both pure liner and liner with $5 \mathrm{wt} \%$ OMMT were characterized with continuous and violent fluctuations in relatively high values, particularly for the one with $5 \mathrm{wt} \%$ OMMT. However, the friction coefficient curve of the liner with $2 \mathrm{wt} \%$ OMMT was very smooth and maintained at a low level. In the engineering application, steady friction is very useful for the smooth running and noise/vibration and breakdown ratio reduction of device parts or equipments. Fig. 15 shows the wear loss of different liner 
at $2 \mathrm{~h}$ for the friction time. It is clear that the liner with $2 \mathrm{wt} \%$ OMMT exhibits the best wear resistance, and both liners with OMMT suffer from less wear loss than the pure liner. Moreover, Fig. 16 compares the wear losses of liner with $2 \mathrm{wt} \%$ and $5 \mathrm{wt} \%$ OMMT at different friction time. Obvious superiority of the liner with $2 \mathrm{wt} \%$ OMMT is observed, and this superiority is enlarging with friction time. The layered structure of the OMMT effectively affects the antifriction property of the liner owing to the decrease of the adhesion and deformation components of the friction force [30]. Besides, the lowered shear deformation of OMMT/polymer composites decreases friction and/or wear of the liner. However, at a higher content of OMMT, the interlayer spacing of OMMT decreased and the mobility of polymer chains was reduced, which hindered the penetration of polymer chains into the interlayer areas of silicate particles, and thus deteriorated the uniform particle dispersion in polymer matrices. Consequently, the particle agglomeration was more pronounced [43]. Particle agglomeration increases the surface roughness and breaks the uniformity of the transfer film and the tribosurface, which in turn accelerates both friction and wear of the liner.

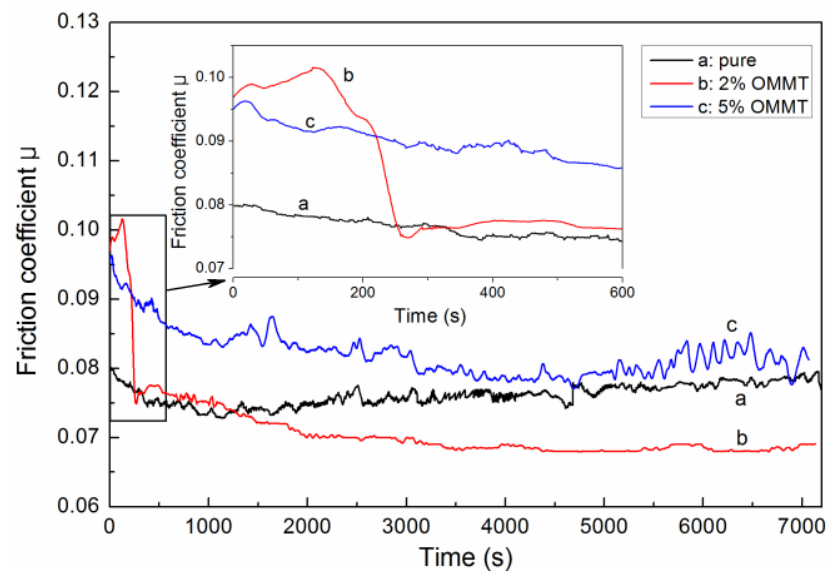

Fig. 14 Friction coefficient of different liners under high velocity/light load friction

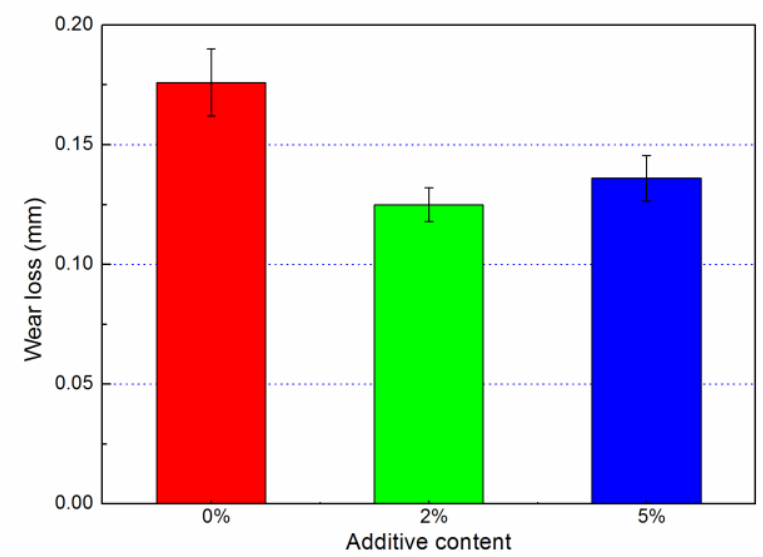

Fig. 15 Wear losses of different liners under high velocity/light load friction 


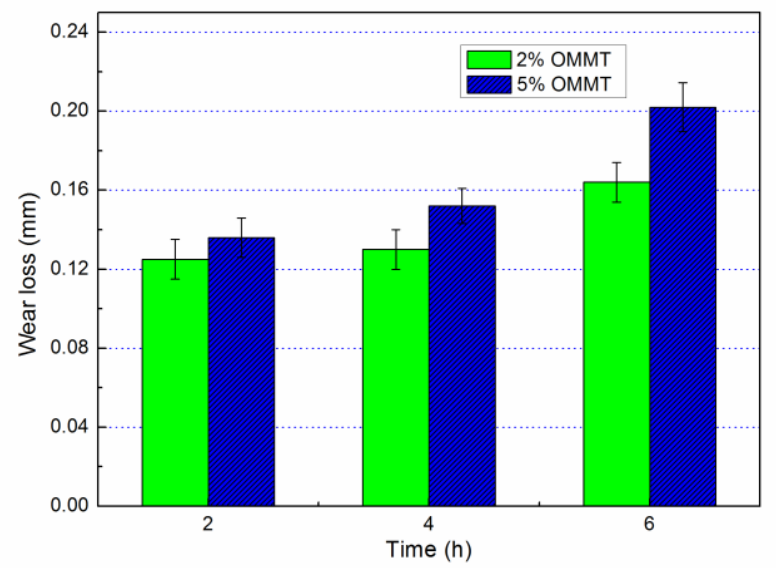

Fig. 16 Wear losses of the liner with $2 \mathrm{wt} \%$ and $5 \mathrm{wt} \%$ OMMT

Wear morphologies of different liners at various friction time are shown in Fig. 17. After $2 \mathrm{~h}$ of friction, severe wear occurred in the pure liner and liner with $5 \mathrm{wt} \%$ OMMT while the wear situation of liner with $2 \mathrm{wt} \%$ OMMT was minor. The worn surface of the pure liner was smooth (image $\alpha$ in Fig. 17) but abrasive wear traces on worn surfaces of both liners with OMMT were obvious (images a- $\beta$ and $\gamma$ in Fig. 17), which might be scratched by peeling off OMMT particles. Liner with 2 wt\% OMMT showed better structure integrity with recognizable weave tissues on worn surface, indicating higher mechanical strength and wear resistance. As the friction continued, wear of all liners appears to be quite severe. Surface fibers of liner with $2 \mathrm{wt} \%$ OMMT were gradually spread out to cover the whole tribosurface, but the warp and weft tissues were still visible as shown in images b- $\beta$ and c- $\beta$ in Fig. 17. The worn surface also became smoother, which was related to the low and steady friction coefficient and wear rate of the liner. Conversely, it can be observed from images b- $\gamma$ and c- $\gamma$ in Fig. 17 that the worn surface of liner with $5 \mathrm{wt} \%$ OMMT turned uneven with lots of pits and deep abrasive traces. The lumpy-looking surface was associated with the fluctuant and high friction coefficient and poor wear resistance of the liner. Overall, the liner with $2 \mathrm{wt} \%$ OMMT exhibits the best structure integrity and smoothest worn surface under high velocity/light load condition, coinciding well with its best antifriction and antiwear properties. 


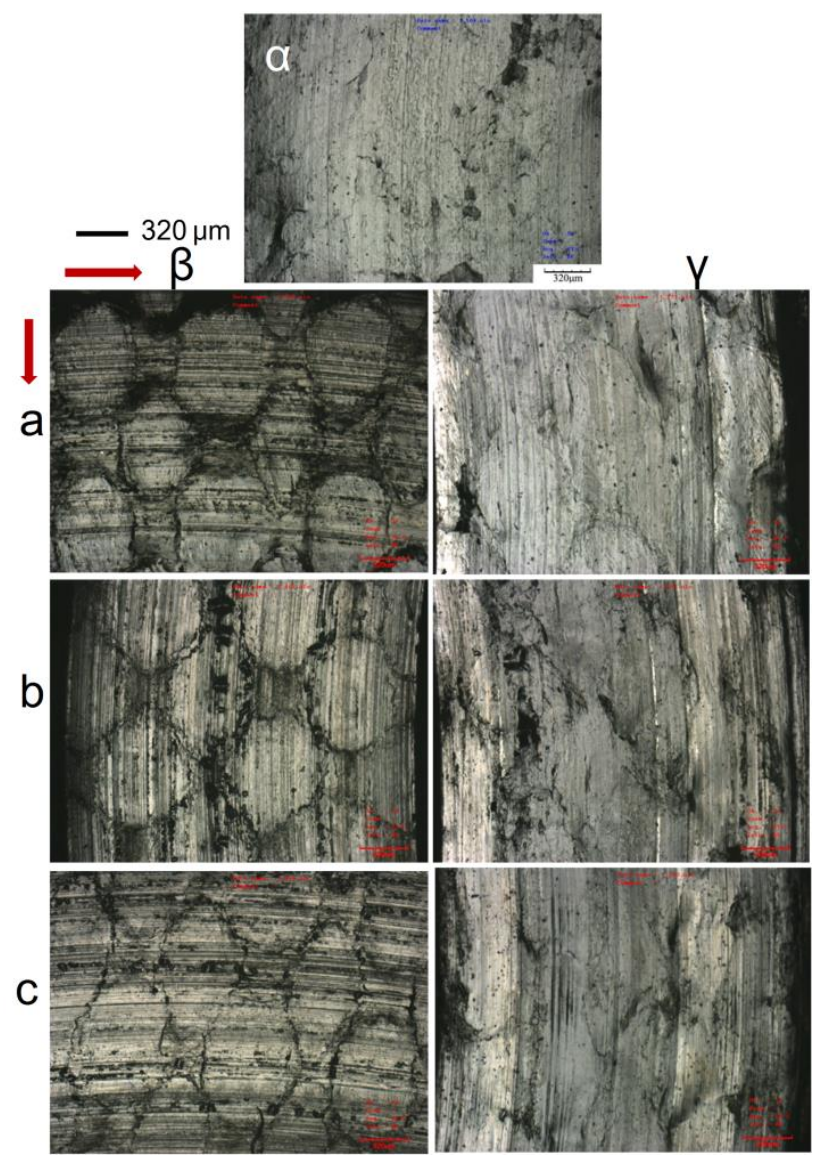

Fig. 17 CLSM wear morphologies of the self-lubricating liners under high velocity/light load condition: $\alpha$ shows the worn surface of pure liner at friction time of $2 \mathrm{~h}$; rows $\beta$ and $\gamma$ indicate liners with $2 \mathrm{wt} \%$ and $5 \mathrm{wt} \%$, respectively; lines of a, b and c indicate the worn image at friction time of $2 \mathrm{~h}, 4 \mathrm{~h}$ and $6 \mathrm{~h}$; all images share the same scale

\section{Conclusion}

OMMT/PF nanocomposites were prepared after conducting two-step intercalation treatment. Taking OMMT/PF nanocomposites into consideration as hybrid matrices, fabric self-lubricating liners with $2 \mathrm{wt} \%$ or $5 \mathrm{wt} \%$ OMMT were manufactured to evaluate the tribological properties compared with pure liner. The following conclusions can be drawn below:

(1) Interlayer spacing of MMT was increased from1.48 nm to $2.07 \mathrm{~nm}$ and $4.27 \mathrm{~nm}$ after the two-step intercalation treatment.

(2) XRD and TEM results of OMMT/PF nanocomposites indicate the complex OMMT dispersion with a mix of intercalated and agglomerated structures. TG-DTG and DSC results show that the thermal stability of the PF matrices was enhanced by the incorporation of OMMT.

(3) Tribological tests indicate a positive effect (enhanced wear resistance, antifriction property and better fabric integrity) of proper content of OMMT on the friction and wear of fabric self-lubricating liner, which is believed to be greatly helpful for the improvement of operation performances and service life of the fabric self-lubricating liner containing parts or equipment. As suggested, the preferable addition content of OMMT is around $2 \mathrm{wt} \%$.

\section{References}

[1] Park, D.C., Lee, S.M., Kim, B.C., Kim, H.S., Lee, D.G.: Development of heavy duty hybrid carbon-phenolic hemispherical bearings. Compos. Struct. 73(1), 88-98 (2006) 
[2] Kim, S.S., Yu, H.N., Hwang, I.U., Kim, S.N., Suzuki, K., Sada, H.: The sliding friction of hybrid composite journal bearing under various test conditions. Tribol. Lett. 35(3), 211-219 (2009)

[3] Lancaster, J.K.: Accelerated wear testing of PTFE composite bearing materials. Tribol. Int. 12, 65-75 (1979)

[4] Rattan, R., Bijwe, J., Fahim, M.: Optimization of weave of carbon fabric for best combination of strength and tribo-performance of polyetherimide composites in adhesive wear mode. Wear 264(1), 96-105 (2008)

[5] Qi, X.W., Ma, J., Jia, Z.N., Yang, Y.L., Gao, H.B.: Effects of weft density on the friction and wear Properties of self-lubricating fabric Liners for journal Bearings under heavy load conditions. Wear 318(1-2), 124-129 (2014)

[6] Azizi Samir, M.A.S., Alloin, F., Dufresne, A.: Review of recent research into cellulosic whiskers, their properties and their application in nanocomposite field. Biomacromolecules 6(2), 612-626 (2005)

[7] Moon, R.J., Martini, A., Nairn, J., Simonsen, J., Youngblood, J.: Cellulose nanomaterials review: structure, properties and nanocomposites. Chem. Soc. Rev. 40(7), 3941-3994 (2011)

[8] Hussain, F., Hojjati, M., Okamoto, M., Gorga, R.E.: Review article: polymer-matrix nanocomposites, processing, manufacturing, and application: an overview. J. Compos. Mater. 40(17), 1511-1575 (2006)

[9] Kurahatti, R.V., Surendranathan, A.O., Kori, S.A., Singh, N., Kumar, A.R., Srivastava, S.: Defence applications of polymer nanocomposites. Defence. Sci. J. 60(5), 551-563 (2010)

[10] Briscoe, B.J., Sinha, S.K.: Tribological applications of polymers and their composites: Past, present and future prospects. In: Tribology and Interface Engineering Series, pp. 1-14. Elsevier (2008)

[11] Njuguna, J., Pielichowski, K.: Polymer nanocomposites for aerospace applications: properties. Adv. Eng. Mater. 5(11), 769-778 (2003)

[12] Winey, K.I., Vaia, R.A.: Polymer nanocomposites. MRS bull. 32(04), 314-322 (2007)

[13] Ray, S.S., Bousmina, M.: Polymer nanocomposites and their applications. Stevenson Ranch, CA: American Scientific (2006)

[14] Wetzel, B., Haupert, F., Qiu Zhang, M.: Epoxy nanocomposites with high mechanical and tribological performance. Compo. Sci. Technol. 63(14), 2055-2067 (2003)

[15] Wetzel, B., Haupert, F., Friedrich, K., Zhang, M.Q., Rong, M.Z.: Impact and wear resistance of polymer nanocomposites at low filler content. Polym. Eng. Sci. 42(9), 1919-1927 (2002)

[16] Cai, H.F., Yan, E., Xue, Q., Liu, W.: Investigation of tribological properties of $\mathrm{Al}_{2} \mathrm{O}_{3}$-polyimide nanocomposites. Polym. Test. 22(8), 875-882 (2003)

[17] Sawyer, W.G., Freudenberg, K.D., Bhimaraj, P., Schadler, L.S.: A study on the friction and wear behavior of PTFE filled with alumina nanoparticles. Wear, 254(5), 573-580 (2003)

[18] Rong, M.Z., Zhang, M.Q., Ruan, W.H.: Surface modification of nanoscale fillers for improving properties of polymer nanocomposites: a review. Mater. Sci. Tech-Lond. 22(7), 787-796 (2006)

[19] Chen, H., Jacobs, O., Wu, W., Rüdiger, G., Schädel, B.: Effect of dispersion method on tribological properties of carbon nanotube reinforced epoxy resin composites. Polym. Test. 26(3), 351-360 (2007)

[20] Zhang, M.Q., Rong, M.Z., Yu, S.L., Wetzel, B., Friedrich, K.: Effect of particle surface treatment on the tribological performance of epoxy based nanocomposites. Wear 253(9), 1086-1093 (2002)

[21] Huang, T., Xin, Y., Li, T., Nutt, S., Su, C., Chen, H., Liu, P., Lai, Z.: Modified graphene/polyimide nanocomposites: reinforcing and tribological effects. ACS Appl. Mater. Inter. 5(11), 4878-4891 (2013)

[22] Min, C., Nie, P., Song, H.J., Zhang, Z., Zhao, K.: Study of tribological properties of polyimide/graphene oxide nanocomposite films under seawater-lubricated condition. Tribol. Int. 80, 
$131-140$ (2014)

[23] Sinha Ray, S., Okamoto, M.: Polymer/layered silicate nanocomposites: a review from preparation to processing. Prog. Polym. Sci. 28(11), 1539-1641 (2003)

[24] Pavlidou, S., Papaspyrides, C.D.: A review on polymer-layered silicate nanocomposites. Prog. Polym. Sci. 33(12), 1119-1198 (2008)

[25] Qi, Z.N., Shang, W.Y.: Theory and Practice of Polymer-Layered Silicate Nanocomposite. Chemical Industry Press, Beijing (2002)

[26] Jo, B.W., Park, S.K., Kim, D.K.: Mechanical properties of nano-MMT reinforced polymer composite and polymer concrete. Constr. Build. Mater. 22(1), 14-20 (2008)

[27] Nikolaidis, A.K., Achilias, D.S., Karayannidis, G.P.: Synthesis and characterization of PMMA/organomodified montmorillonite nanocomposites prepared by in situ bulk polymerization. Ind. Eng. Chem. Res. 50(2), 571-579 (2010)

[28] Hu, D., Chen, J., Sun, S., Liu, T., Zhao, L.: Solubility and Diffusivity of $\mathrm{CO}_{2}$ in Isotactic Polypropylene/Nanomontmorillonite Composites in Melt and Solid States. Ind. Eng. Chem. Res. 53(7), 2673-2683 (2014)

[29] Manias, E., Touny, A., Wu, L., Strawhecker, K., Lu, B., Chung, T.C.: Polypropylene/montmorillonite nanocomposites. Review of the synthetic routes and materials properties. Chem. Mater. 13(10), 3516-3523 (2001)

[30] Novakov, I.A., Rakhimova, N.A., Nistratov, A.V., Kudashev, S.V., Gugina, S.Y.: Structure and tribological behavior of polydiene urethanes based on oligomeric compositions modified by polyfluorine alkyl organophilic montmorillonite. J. Frict. Wear+ 32(4), 258-268 (2011)

[31] Novakov, I.A., Rakhimova, N.A., Nistratov, A.V., Kudashev, S.V., Gugina, S.Y.: Synthesis, structure, properties, and tribological behavior of materials based on polythio urethanes modified by polyfluorine-and copper-containing Na+-montmorillonite under conditions of thermo-oxidative and light aging. J. Frict. Wear+ 32(5), 356-367 (2011)

[32] Yu, Y., Gu, J., Kang, F., Kong, X., Mo, W.: Surface restoration induced by lubricant additive of natural minerals. Appl. Surf. Sci. 253(18), 7549-7553 (2007)

[33] Pogodaev, L.I., Buyanovskii, I.A., Kryukov, E.Y., Kuz'min, V.N., Usachev, V.V.: The mechanism of interaction between natural laminar hydrosilicates and friction surfaces. J. Mach. Manuf. Reliab. 38(5), 476-484 (2009)

[34] Alexandre, M., Dubois, P.: Polymer-layered silicate nanocomposites: preparation, properties and uses of a new class of materials. J. Mat. Sci. Eng. R. 28(1), 1-63 (2000)

[35] Wu, Z., Zhou, C., Qi, R.: The preparation of phenolic resin/montmorillonite nanocomposites by suspension condensation polymerization and their morphology. Polym. Composite. 23(4), 634-646 (2002)

[36] Jiang, W., Chen, S.H., Chen, Y.: Nanocomposites from phenolic resin and various organo-modified montmorillonites: Preparation and thermal stability. J. Appl. Polym. Sci. 102(6), 5336-5343 (2006)

[37] Yang, Y.L., Ma, J., Qi, X.W., Meng, X.S.: Fabrication of Nano Serpentine-Potassium Acetate Intercalation Compound and Its Effect as Additive on Tribological Properties of the Fabric Self-lubricating Liner. Wear 318(1-2), 202-211 (2014)

[38] Yu, T., Lin, J., Xu, J., Chen, T., Lin, S., Tian, X.: Novel polyacrylonitrile/Na-MMT/silica nanocomposite: Co-incorporation of two different form nano materials into polymer matrix. Compos. Sci. Technol. 67(15), 3219-3225 (2007) 
[39] Xing, J., Deng, B., Liu, Q.: Preparation and thermal properties of polyphenylene sulfide/organic montmorillonite composites. Fiber. Polym. 15(8), 1685-1693 (2014)

[40] Lin, J.M., Ma, C.C.M.: Thermal degradation of phenolic resin/silica hybrid ceramers. Polym. Degrad. Stabil. 69(2), 229-235 (2000)

[41] Ooi, Z.X., Ismail, H., Bakar, A.A.: Thermal properties and aging characteristics of chemically modified oil palm ash-filled natural rubber composites[J]. Iran. Polym. J. 23(9): $723-730$ (2014)

[42] Ye, J., Khare, H.S., Burris, D.L.: Transfer film evolution and its role in promoting ultra-low wear of a PTFE nanocomposite. Wear 297, 1095-1102 (2013)

[43] Chang, I.T., Sancaktar, E.: Clay dispersion effects on excimer laser ablation of polymer-clay nanocomposites. J. Appl. Polym. Sci. 130(4), 2336-2344 (2013) 